\title{
PENGARUH AKTIVITAS RIPPING-DOZING TERHADAP PRODUKTIVITAS PENGUPASAN OVERBURDEN DI PT BUKIT ASAM
}

\section{EFFECT OF RIPPING-DOZING ACTIVITY ON PRODUCTIVITY OF OVERBURDEN STRIPPING AT PT BUKIT ASAM}

\author{
BY. Baklaes ${ }^{1 *}$, MT. Toha ${ }^{2}$, Azwardi $^{3}$ \\ ${ }^{1-2}$ Magister Teknik Pertambangan, Fakultas Teknik, Universitas Sriwijaya \\ ${ }^{3}$ Ekonomi Pembangunan, Fakultas Ekonomi, Universitas Sriwijaya \\ e-mail: ${ }^{* 1}$ barabaklaes@gmail.com, ${ }^{2}$ taufik toha@yahoo.com, ${ }^{3}$ azwardi_unsri@yahoo.com
}

\section{ABSTRAK}

Tahapan penambangan yang dilakukan sebelum mengambil mineral berharga atau batubara adalah pengupasan tanah penutup (overburden). Metode yang biasa dilakukan untuk mengupas tanah penutup yang memiliki kekuatan batuan tingkat sedang adalah dengan menggunakan metode penggaruan (ripping). Penelitian ini bertujuan untuk melihat pengaruh aktivitas Ripping-Dozing terhadap produktivitas pengupasan overburden di area penambangan Pit 1 Utara Banko barat. Hal ini dikarenakan pada periode Juni - Agustus 2020 produktivitas excavator komatsu PC 2000 setiap bulan secara berurutan sebesar 514,92 BCM/jam, 514,92 BCM/jam, dan $508.9 \mathrm{BCM} / \mathrm{jam}$, sementara target produksi perusahaan adalah 640 $\mathrm{BCM} / \mathrm{jam}$. Data primer berupa waktu edar alat gali-muat (excavator komatsu PC 2000) dan angkut (dumptruck komatsu HD 785), waktu edar bulldozer komatsu D375, kedalaman penetrasi ripper, faktor pengembangan (swell factor). Data sekunder terdiri dari peta lokasi, spesifikasi peralatan excavator, bulldozer, dumptruck. Pengolahan data dilakukan dengan menghitung produktivitas alat gali-muat, produktivitas alat angkut saat dilakukan kegiatan ripping dan saat kombinasi ripping-dozing, dan produktivitas ripping, poduktivitas dozing proses pengupasan material overburden. Hasil pengolahan data menunjukkan hasil bahwa produktivitas alat angkut meningkat dari $415 \mathrm{BCM} / \mathrm{jam}$ saat dilakukan ripping menjadi 640 $\mathrm{BCM} / \mathrm{jam}$ saat dilakukan aktivitas Ripping-Dozing. Hal ini menyebabkan produkivitas dari alat angkut juga meningkat dari 101,62 BCM/jam menjadi 113,57 BCM/jam. Produktivitas bulldozer menurun dari 864 BCM/jam menjadi 413 BCM/jam. Artinya, aktivitas Ripping-Dozing lebih efektif digunakan dalam kegiatan pemberaian material overburden ditunjukkan dengan meningkatnya produktivitas dari alat gali-muat dan angkut, sehingga target produksi dapat dicapai.

Kata kunci: Ripping, Ripping-Dozing, produktivitas, alat gali-muat, alat angkut

\section{ABSTRACT}

The stages of mining activities carried out before extracting valuable minerals or coal are overburden stripping. The usual method is to strip overburden which has rock strength the medium level is to use the ripping method. This study aims to see the effect of Ripping-Dozing activity on the productivity of overburden stripping in the mining area of Pit 1 Utara Banko barat. This is because in the period of June - August 2020 the productivity of the Komatsu PC 2000 excavator every month is $514.92 \mathrm{BCM} /$ hour, $514.92 \mathrm{BCM} /$ hour, and $508.9 \mathrm{BCM} /$ hour, while the company's production target is 640 BCM / hour. The primary data consist of dig-load (excavator PC 2000) and transport (Komatsu HD 785 dumptruck), delivery time of the Komatsu D375 bulldozer, ripper penetration depth, and swell factor. Secondary data consists of location maps, excavator equipment specifications, bulldozers, dump trucks. Data processing is done by calculating the productivity of the dig-and-load tool, the productivity of the conveyance during the ripping activity and when the ripping-dozing combination is carried out, and the productivity of ripping, the dozing productivity of the overburden stripping process. The results of data processing show that the productivity of the transportation equipment increases from 415 BCM / hour when ripping is done to 640 BCM / hour when the Ripping-Dozing activity is carried out. This causes the productivity of transportation equipment to also increase from 101.62 BCM / hour to 113.57 BCM / hour. Bulldozer productivity decreased from 864 BCM / hour to 413 BCM / hour. This means that the Ripping-Dozing activity is more effectively used in the activity of unloading the overburden material as indicated by the increased productivity of the digging and loading equipment so that production targets can be achieved.

Key words: Ripping, Ripping-Dozing, productivity, digging equipment, transportation equipment 


\section{PENDAHULUAN}

Penambangan adalah rangkaian kegiatan yang dilakukan dengan cara penggalian, pemuatan, dan pengangkutan untuk mendapatkan komoditas tambang [1]. Tahapan penambangan batubara yang dilakukan terdiri dari pembersihan lahan, pengelolaan topsoil, pengupasan overburden, penggalian batubara, pemuatan, pengangkutan, prosesing dan penjualan, serta reklamasi [2]. Kegiatan penggalian atau tanah penutup (overburden) merupakan kegiatan yang dilakukan sebelum mengambil mineral atau batubara yang terdapat di bawah permukaan bumi. Kondisi batuan yang ada pada lapisa overburden menjadi faktor penentu dalam menggunakan metode pemberaian yang tepat. Metode yang dapat diterapkan dalam memberai batuan seperti penggalian secara langsung (free digging), pemboran-peledakan (drillingblasting) dan penggaruan (Ripping), [3]. Ripping adalah tata cara memberai material memakai ripper pada bulldozer [4]. Adapun tujuan metode ripping adalah mengoptimalkan kinerja ripper bulldozer pada saat proses Ripping supaya menciptakan fragmentasi hasil Ripping yang baik. Kemampugaruan dari suatu material tersebut dapat ditentukan melalui nilai uji kuat tekan batuan (UCS).

Mekanisme penggaruan (Ripping) sebagai berikut [5]:

1. Ploughing merupakan penggaruan yang diterapkan pada material padat tanpa bidang lemah, spasi penggaruan rapat, serta jumlah material terbongkar kecil.

2. Crushing merupakan penggaruan yang dilakukan pada material dengan kondisi spasi bidang lemah rapat $(0,1-0,3 \mathrm{~m})$.

3. Lifting merupakan penggaruan yang dilakukan pada material dengan strata horizontal, lempengan material terangkat yang kemudian terbongkar.

4. Breaking merupakan penggaruan yang dilakukan pada material dengan strata miring (inclined).

Metode Ripping yang biasa diterapkan adalah metode Ripping berdampingan dan cross Ripping (Gambar 1). Metode Ripping (garu) berdampingan dilakukan pada material yang relatif mudah terbongkar. Cara penggaruan metode ini adalah dilakukan secara sejajar. Ripper bergerak ke samping sampai seuruh area garu terbognkar dengan spasi tertentu [6]. Metode cross Ripping dilakukan pada material yang relatif lebih keras atau sulit untuk dibongkar. Cara penggaruan hamper sama dengan metode garu berdampingan hanya saja dilakukan juga penggaruan dengan arah tegak lurus garu sebelumnya [6]. Ukuran garu yang dihasilkan cenderung lebih kecil dimana ditetapkan berdasarkan kemampuan alat muat atau syarat ukuran feed crusher.

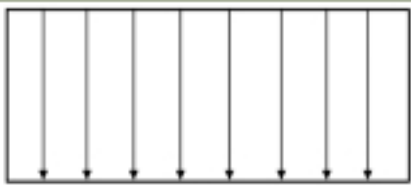

(a) (b)
Gambar 1. Metode (a) garu berdampingan (b) cross ripping [6]

Aktivitas pemberaian batuan tidak hanya Ripping saja, namun juga dapat dikombinasikan dengan kegiatan Dozing. Aktivitas Ripping-Dozing dilakukan dengan cara melakukan kegiatan Ripping atau penggaruan terlebih dahulu, kemudian material hasil Ripping tersebut didorong ke arah alat gali-muat untuk dijadikan umpan penggalian berikutnya dan memudahkan bulldozer untuk melakukan proses Ripping pada lapisan bawahnya [3].

PT Bukit Asam Tbk memiliki beberapa area penambangan batubara. Salah satunya adalah Banko Barat khususnya di area pit 1 Utara yang saat ini menggunakan metode Ripping untuk membongkar material lapisan overburden. Hal ini dikarenakan material overburden-nya berupa claystone dengan nilai kuat tekan batuan senilai 2,307 mpa yang tergolong kemampugaruan materialnya termasuk material lunak. Selain itu kegiatan ripping di perusahaan ini dilakukan karena kemampuan gali dari alat excavator komatsu PC 2000 sebesar $626 \mathrm{KN}$ atau setara dengan 0,626 mpa. Peralatan yang digunakan pada kegiatan penambangan di Pit 1 Utara Banko Barat saat ini terdiri dari excavator komatsu PC 2000 dan PC 1250 untuk alat loader-nya, sedangkan untuk alat hauler-nya menggunakan dumptruck komatsu HD 785 dan OHT caterpillar 777. Ketersediaan alat serta metode yang digunakan dalam proses pemberaian material overburden menjadi penting dalam kegiatan penambangan. Hal ini berkaitan erat dengan ketercapaian target produksi hasil pemberaian.

Target produksi perusahaan untuk pengupasan tanah penutup untuk setiap bulannya adalah $640 \mathrm{BCM} / \mathrm{jam}$. Sementara produksi pengupasan tanah penutup pada periode Juni - Agustus 2020 produktivitas excavator komatsu PC 2000 setiap bulan secara berurutan sebesar $514,92 \mathrm{BCM} / \mathrm{jam}, \quad 514,92 \mathrm{BCM} / \mathrm{jam}$, dan 508.9 $\mathrm{BCM} / \mathrm{jam}$ yang artinya tidak mencapai target produksi yang telah ditetapkan perusahaan. Kegiatan pengupasan tanah penutup saat ini dilakukan dengan menggunakan metode straight ripping. Berdasarkan hal tersebut perlu dilakukannya inovasi terhadap metode pengupasan yang dilakukan. Salah satunya adalah dengan menerapkan metode ripping yang dikombinasikan dengan dozing. Aktivitas ripping-dozing dilakukan dengan cara ripper dimasukan (penetrasi) ke tanah kemudian dilakukan seiring dengan maju dan mundur, kemudian untuk dozing komponen bulldozer berupa blade mendorong 
material yang sudah di-ripping. Penerapan metode ripping-dozing ini diharapkan dapat memberikan solusi kepada perusahaan untuk dapat mencapai target produksi yang telah ditetapkan. Penelitian ini bertujuan untuk melihat pengaruh aktivitas Ripping-Dozing terhadap produktivitas alat gali-muat berupa excavator komatsu PC 2000.

\section{METODE PENELITIAN}

Penelitian dilakukan di PT Bukit Asam, di area Banko barat khususnya di area Pit 1 Utara. Gambar 2 menunjukan peta regional lokasi penelitian.

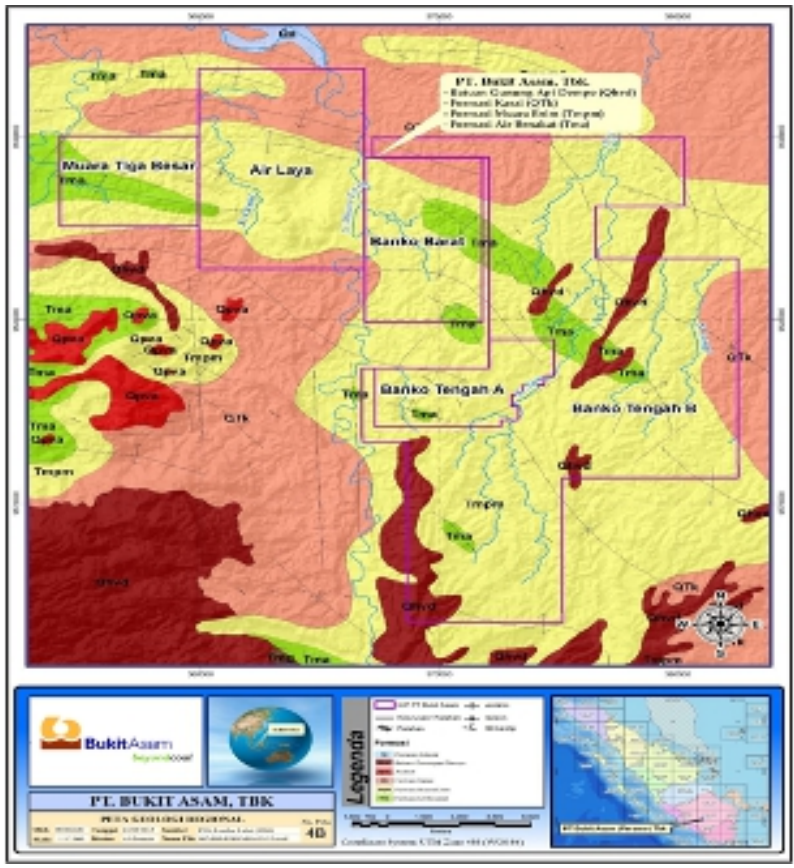

Gambar 2. Peta regional PT. Bukit Asam Tbk

Data primer berupa tinggi jenjang waktu edar alat galimuat dan angkut, waktu edar peralatan bulldozer, kedalaman penetrasi ripper, faktor pengembangan (swell factor) yang digunakan dalam perhitungan produktivitas alat jika menerapkan aktivitas ripping dan aktivitas ripping-dozing. Data sekunder terdiri dari peta lokasi, spesifikasi alat gali-muat berupa excavator komatsu PC 2000, alat angkut berupa dumptruck komatsu HD 785, dan alat garu dan dozing berupa bulldozer komatsu D375.

Perhitungan produktivitas dilakukan untuk mengetahui produktivitas dari alat gali-muat dan angkut dari kegiatan pembongkaran tanah penutup dengan metode Ripping dan pembongkaran tanah penutup dengan metode Ripping-Dozing. Perhitungan menggunakan perumusan sebagai berikut.

1. Waktu edar alat gali-muat
Waktu edar alat gali-muat menggunakan Pers.(1) sebagai berikut [7]:

$\mathrm{Cm}=\mathrm{Tm} 1+\mathrm{Tm} 2+\mathrm{Tm} 3+\mathrm{Tm} 4$

Keterangan:

$\begin{array}{ll}\mathrm{Cm} & =\text { Cycle time (detik) } \\ \mathrm{Tm} 1 & =\text { waktu penggalian (detik) } \\ \mathrm{Tm} 2 & =\text { waktu swing isi (detik) } \\ \mathrm{Tm} 3 & =\text { waktu dumping (detik) } \\ \mathrm{Tm} 4 & =\text { waktu swing kosong (detik) }\end{array}$

2. Perhitungan faktor pengembang atau swell factor Data ini diperlukan agar didapat faktor pengembangan atau swell factor untuk area Pit 1 Utara. Pengambilan data ini dilakukan dengan cara mengambil data di area yang akan digali (insitu) dengan menggunakan alat survey berupa Geodetic dan data yang sudah digali di area disposal (loose). Kemudian setelah data ini di dapat data tersebut di olah dengan menggunakan software 12D Setelah data di olah di software $12 \mathrm{D}$, data akan di dapatkan dan data tersebut akan di gunakan untuk perhitungan produktivitas excavator komatsu PC 2000.

3. Produktivitas alat gali-muat

Produktivitas alat gali-muat menggunakan Pers.(2) sebagai berikut [8]:

$P=\frac{3600}{C t} x K b x F b x E f f x S F$

Keterangan:

$\mathrm{P} \quad=$ Produktivitas alat gali-muat, $(\mathrm{BCM} / \mathrm{jam})$

$\mathrm{Kb} \quad=$ Kapasitas bucket back hoe, $\left(\mathrm{m}^{3}\right)$

$\mathrm{Fb} \quad=$ Faktor bucket $(\mathrm{K})$

Eff = Efisiensi kerja backhoe, $(\%)$

$\mathrm{SF} \quad=$ Swell Factor

$\mathrm{Ct}=$ Cycle time (detik)

4. Waktu siklus bulldozer

Waktu siklus bulldozer menggunakan Pers.(3) berikut [9]:

$c m=\frac{D}{F} x \frac{D}{R}+Z$

Dimana :

$\mathrm{D} \quad=$ jarak angkut (meter)

$\mathrm{F} \quad=$ kecepatan maju (m/menit)

$\mathrm{R} \quad=$ kecepatan mundur $(\mathrm{m} / \mathrm{menit})$

$\mathrm{Z} \quad$ = waktu ganti persnelling (menit)

5. Produktivitas ripping

Produktivitas ripping menggunakan Pers.(4) berikut:

$q_{r}=\frac{1 / 2 x P^{2} x J x 60 x F K}{c m}$

Keterangan: 


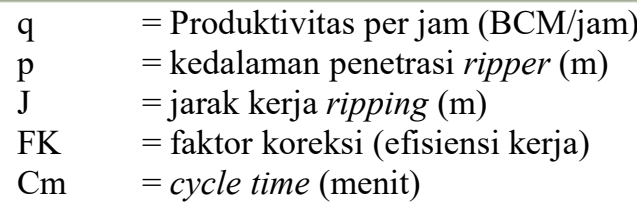

6. Produktivitas alat angkut

Produktivitas alat angkut menggunakan Pers.(5) sebagai berikut [10]:

$\mathrm{P}=\mathrm{nx} \mathrm{q} 1 \mathrm{x} \mathrm{Kx} \frac{\mathrm{3} 600}{\mathrm{Ctm}} \mathrm{x}$ Et $\mathrm{xM}$

Keterangan :

$\mathrm{P} \quad=$ produktivitas alat angkut

$\mathrm{n}$ = banyaknya jumlah pengisian

$\mathrm{q} 1=$ Kapasitas bucket excavator $\left(\mathrm{m}^{3}\right)$

$\mathrm{K}=$ nilai Bucket Fill Factor Excavator

$\mathrm{C}=$ produksi per siklus

$\mathrm{Ctm}=$ cycle time alat angkut (detik)

$\mathrm{Et}=$ efisiensi kerja

$\mathrm{M}$ = jumlah alat angkut yang beroperasi

7. Keserasian Alat

Keserasian alat (matching factor) dihitung dengan Pers.(6) berikut:

$\mathrm{MF}=(\mathrm{n}) \cdot(\mathrm{n} \cdot \mathrm{H}) \cdot(\mathrm{cL}) /(\mathrm{n} \cdot \mathrm{L}) \cdot(\mathrm{cH})$

Dimana:

$\mathrm{n} \quad=$ banyak bucket alat muat

$\mathrm{nH}=$ Banyak alat angkut

$\mathrm{cL}=$ Waktu edar alat muat

$\mathrm{cH}=$ Waktu edar alat angkut

$\mathrm{nL}=$ Jumlah alat muat

Analisis terhadap keserasian alat gali-muat dan angkut dijelaskan sebagai berikut:

a. $\mathrm{MF}=1$, artinya bahwa alat gali-muat dan alat angkut bekerja serasi dimana tidak saling menunggu

b. $\mathrm{MF}<1$, artinya bahwa alat angkut bekerja penuh waktu sementara alat muat mempunyai waktu tunggu.

c. $\mathrm{MF}>1$, artinya bahwa alat muat bekerja penuh waktu sementara alat angkut mempunyai waktu tunggu)

8. Produktivitas Dozing

Produktivitas bulldozer saat Dozing dihitung menggunakan Pers. (7) sebagai berikut:

$q_{d}=\frac{K B \times 60 \times F K}{\frac{J}{F}+\frac{J}{R}+Z}$

Keterangan:

$\mathrm{q}_{\mathrm{d}}=$ produktivitas Dozing bulldozer

$\mathrm{KB} \quad=$ Kapasitas Blade

FK $\quad=$ Efisiensi kerja
$\mathrm{D}=$ jarak angkut $(\mathrm{m})$

$\mathrm{F} \quad=$ kecepatan maju $(\mathrm{m} / \mathrm{menit})$

$\mathrm{R} \quad=$ kecepatan mundur (m/menit)

$\mathrm{Z} \quad$ = waktu ganti persnelling (menit)

9. Kapasitas produksi Ripping-Dozing

Kapasitas produksi Ripping-Dozing dihitung menggunakan Pers.(8) sebagai berikut:

$q_{r d}=\frac{q_{d} x q_{r}}{q_{d} x q_{r}}$

Keterangan:

$\mathrm{q}_{\mathrm{rd}} \quad=$ produktivitas Ripping-Dozing

$\mathrm{q}_{\mathrm{r}} \quad=$ produktivitas Ripping

$\mathrm{q}_{\mathrm{d}} \quad=$ produktivitas Dozing

Analisis produktivitas alat gali-muat dilakukan dengan memperhatikan 3 parameter yaitu tinggi jenjang, metode ripping, dan jarak antar ripping. Hasil perhitungan produktivitas alat pada aktivitas ripping dan pada aktivitas ripping-dozing yang diperoleh selanjutnya dilakukan analisis perbandingan untuk mengetahui manakah yang lebih efisien dan efektif serta dapat memenuhi target produksi perusahaan. Berdasarkan hasil analisis maka dapat direkomendasikan metode pengupasan tanah penutup yang terbaik.

\section{HASIL DAN PEMBAHASAN}

Produktivitas Alat dan Faktor Keserasian

Kegiatan penggalian tanah menggunakan excavator komatsu PC 2000 dan untuk pemberaian material tanah dengan menggunakan bulldozer D375. Berdasarkan pengamatan aktivitas pengupasan tanah penutup yang dilaksanakan di lapangan, diperoleh hasil pengamatan berupa waktu edar alat gali-muat excavator komatsu PC 2000, alat ripping bulldozer komatsu D375, dan alat angkut dumptruck komatsu HD 785.

a. Produktivitas Alat Gali-Muat

Perhitungan produktivitas alat gali-muat excavator Komatsu PC 2000 dihitung dengan memakai Pers.(2) seperti berikut:

Diketahui:

Kapasitas bucket $\quad=12 \mathrm{~m}^{3}$

Bucket Fill Factor $\quad=85$

Effisiensi kerja (Eff) $\quad=76 \%$

Swell factor $\quad=87 \%$

Cycletime PC $2000=59$ detik

$P=\frac{3600}{59} \times 12 \times 0,85 \times 0,76 \times 0,87=415 \mathrm{bcm} / \mathrm{jam}$ 
Berdasarkan hasil perhitungan dapat diketahui bahwa produktivitas alat gali-muat masih belum memenuhi target produksi perusahaan. Berdasarkan pengamatan beberapa hal yang mempengaruhi dari produktivitas alat gali-muat adalah kondisi tinggi jenjang antara alat galimuat excavator komatsu PC 2000 dengan alat angkutnya, cycle time yang relatif masih tinggi serta metode ripping yang dilakukan oleh alat ripping bulldozer komatsu D375 masih belum maksimal.

\section{Tinggi jenjang}

Kondisi dari tinggi jenjang (bench) juga bisa mempengaruhi produktivitas excavator. Hasil galian yang maksimal dapat dicapai jika tinggi jenjang pijakan yang optimum yaitu antara $40 \%$ - 75\% dari kedalaman maksimum yang dapat di jangkau oleh excavator [11].

Jika tinggi jenjang(bench) terhadap material yang akan digali tidak memiliki tinggi yang mencukupi, akan sulit untuk mengisi bucket sampai penuh dalam satu kali passing.

Jika dilihat pada Gambar 3 kondisi tinggi jenjang antara loading point excavator komatsu PC 2000 dan alat angkut dumptruck komatsu HD785 dapat dikatakan belum ideal karena masuk dalam kategori tinggi jenjang di bawah $40 \%$.

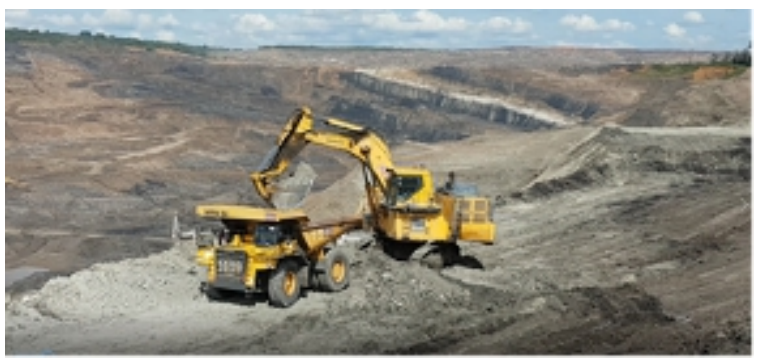

Gambar 3. Kondisi tinggi jenjang PC 2000

Waktu edar merupakan waktu yang dibutuhkan suatu alat melaksanakan kegiatan tertentu. Pada setiap kegiatan pemindahan tanah mekanis, alat mekanis bekerja menurut pola tertentu dengan prinsip beberapa komponen waktu siklus dan gerakan dalam satu siklus waktu [12]. Cycle time yang dapat pada saat di lakukan penelitian adalah sebesar 58 detik. Hal ini juga dapat mempengaruhi dari produktivitas dari gali-muat excavator komatsu PC 2000.

\section{Metode Ripping}

Metode ripping yang dilakukan pada aktivitas penambangan di pit 1 Utara Banko Barat yaitu dengan menggunakan teknik straight Ripping dengan jarak antar ripping adalah 1 meter (Gambar 4).
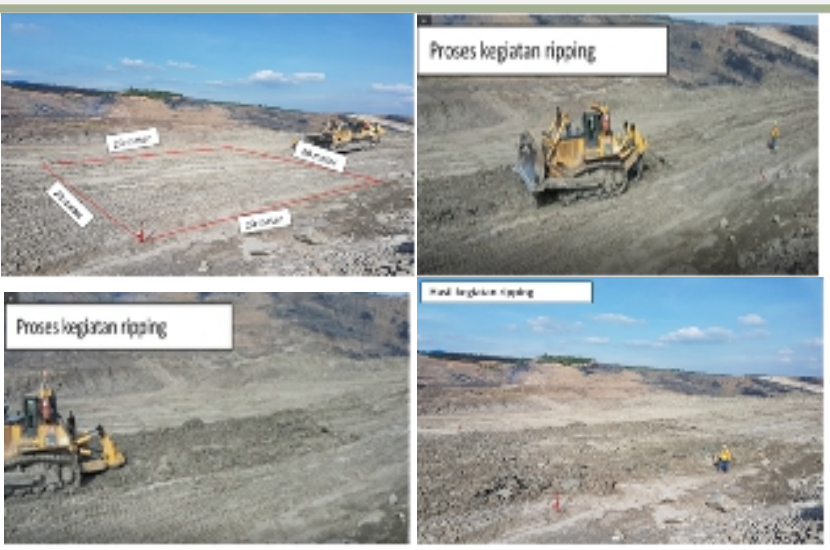

Gambar 4. Kegiatan ripping

3. Jarak antar Ripping

Kedalaman ripping diukur dengan menggunakan alat meteran. Hasil yang di dapat adalah kedalaman penetrasi ripping sebesar 1,2 meter (Gambar 5).

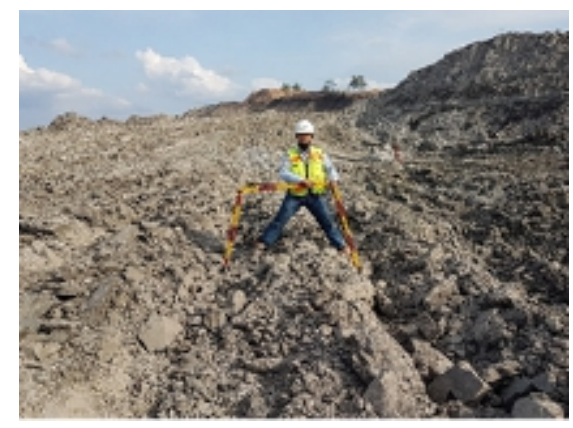

Gambar 5. Pengukuran kedalaman penetrasi ripping

b. Produktivitas Ripping

Waktu siklus alat ripping bulldozer dihitung dengan menggunakan Pers.(3) sebagai berikut:

Diketahui:

Kapasitas blade $(\mathrm{KB}) \quad=22 \mathrm{~m}^{3}$

Jarak dorong (D) $\quad=20 \mathrm{~m}$

Waktu maju dozer $\quad=26$ detik

Waktu mundur dozer $\quad=16$ detik

Waktu pergantiaan transmisi $=3$ detik

$\mathrm{F}=20 / 26=0,77$

$\mathrm{R}=20 / 16=1,25$

$\mathrm{CM}=(20 / 0,77)+(20 / 1,25)+2=26+16+2$

$=44$ detik atau 0,73 menit

Produktivitas Bulldozer D375 dihitung dengan menggunakan Pers.(4) sebagai berikut: 
Diketahui:

Luas area garu (LA)

Kedalaman Penetrasi

$=400 \mathrm{~m}^{2}$

Panjang Area (J)

Efisiensi Kerja

$=1,2 \mathrm{~m}$

$=20 \mathrm{~m}$

$=0,85$

$q_{r}=\frac{1 / 2 \times 1,2 \times 1,2 \times 60 \times 0,75}{0,75}=864 \mathrm{bcm} / \mathrm{jam}$

c. Produktivitas Alat Angkut

Material clay stone dari loading excavator komatsu PC 2000 diangkut menggunakan dumptruck komatsu HD 785 dengan jarak tempuh dari loading point ke disposal 4,6 km. Waktu edar unit dumptruck adalah 1462,2 detik. Produktivitas alat angkut dihitung menggunakan Pers.(5) sebagai berikut:

Diketahui:

$\begin{array}{ll}\text { Kapasitas bucket }(\mathrm{KB}) & =12 \mathrm{~m}^{3} \\ \text { Banyak pengisian(n) } & =5 \mathrm{kali} \\ \text { Factor bucket }(\mathrm{Fb}) & =90 \\ \text { Effisiensi kerja(Eff) } & =76 \% \\ \text { Swell factor(SF) } & =0,87 \\ \text { Cycle time HD 785 } & =24 \text { menit }\end{array}$

$P=5 x 12 \times 90 x \frac{3600}{1462,2} 0,76 \times 0,87=101,62 \mathrm{bcm} / \mathrm{jam}$

d. Keserasian alat gali-muat dan angkut

Keserasian alat dihitung dengan Pers.6, seperti berikut:

$$
\begin{aligned}
\mathrm{MF} & =(5 \times 6 \times 58) /(1 \times 1462,2) \\
& =1740 / 1462,2 \\
& =1,19
\end{aligned}
$$

Berdasarkan hasil perhitungan terlihat bahwa bernilai 1,19 artinya nilai $\mathrm{MF}>1$ dimana alat muat bekerja penuh sementara alat angkut mempunyai waktu tunggu.

Pengaruh Aktivitas Ripping-Dozing Terhadap Produkivitas Alat

Simulasi kegiatan penambangan dengan melakukan aktivitas Ripping-Dozing dilakukan pada area penambangan di Pit 1 Utara Banko Barat dengan menggunakan alat gali-muat berupa excavator komatsu PC 2000, alat angkut berupa dumptruck komatsu HD 785 beserta alat untuk aktivitas ripping-dozing berupa bulldozer komatsu D375. Hasil yang didapat dengan melakukan aktivitas Ripping-Dozing ini berhasil untuk meningkatkan produktivitas alat gali-muat yaitu excavator komatsu PC 2000 untuk mencapai target produksi sebesar $640 \mathrm{BCM} / \mathrm{jam}$.

\section{a. Produktivitas Alat Gali-Muat}

Perhitungan produktivitas alat gali-muat excavator komatsu PC 2000 dihitung dengan menggunakan Pers.2 sebagai berikut:
Diketahui:

Kapasitas bucket $\quad=12 \mathrm{~m}^{3}$

Bucket Fill Factor $\quad=100 \%$

Effisiensi kerja (Eff) $\quad=76 \%$

Swell factor $\quad=87 \%$

Cycle time PC $2000=45$ detik

$P=\frac{3600}{45} \times 12 \times 100 \% \times 0,79 \times 0,87=640 \mathrm{bcm} / \mathrm{jam}$

Berdasarkan perhitungan produktivitas alat gali-muat didapatkan nilai $640 \mathrm{BCM} / \mathrm{jam}$. Hal ini tidak lepas dari improvement yang dilakukan di lapangan mulai dari perbaikan tinggi jenjang (bench), perubahan metode Ripping menjadi Ripping-Dozing pada alat garu bulldozer komatsu D375.

1. Tinggi jenjang (bench)

Perbaikan tinggi jenjang yang dilakukan di lapangan secara langsung berdampak terhadap peningkatan produktivitas alat gali-muat. Pada Gambar 6 di atas terlihat jenjang (bench) yang ada merupakan tinggi jenjang yang optimum untuk kegiatan loading tanah. Pada kondisi seperti ini alat gali-muat excavator komatsu PC 2000 dapat melakukan kegiatan penggalian dengan optimum dan dapat meningkatkan bucket fill factor dan memperkecil cycle time, sehingga hasil yang didapat adalah peningkatan produktivitas dari alat galimuat.

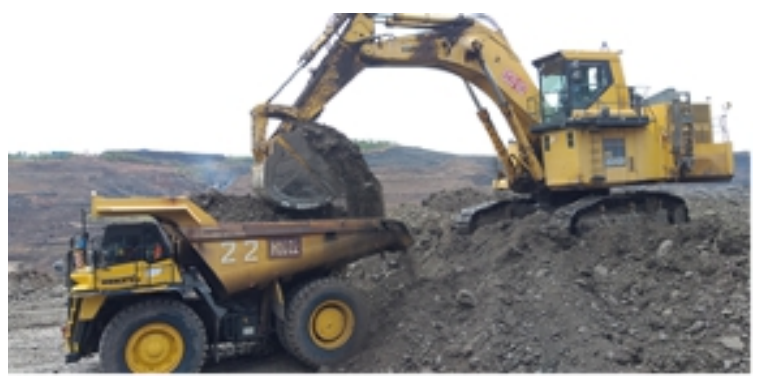

Gambar 6. Tinggi jenjang yang optimum

2. Waktu Edar Alat Gali-Muat

Perbaikan dilaksanakan dengan tujuan untuk meningkatkan produktivitas alat gali-muat, tidak lepas dari penurunan angka dari cycle time alat gali-muat, yang awalnya diperoleh waktu edar senilai 59 detik menjadi 45 detik.

\section{Metode Ripping}

Metode Ripping yang dilakukan mengalami perubahan yang awalnya hanya kegiatan Ripping saja kemudian ditambahkan dengan kegiatan Ripping dan Dozing, sehingga hal ini dapat membuat peningkatan produktivitas alat gali-muat komatsu PC 2000. Metode kerjanya adalah awalnya bulldozer melakukan kegiatan 
Ripping, kemudian setelah Ripping dilakukan Dozing yang bertujuan untuk memberikan suplay material (feeding) ke alat gali-muat hal ini bisa di jelaskan dengan simulasi Gambar 7.

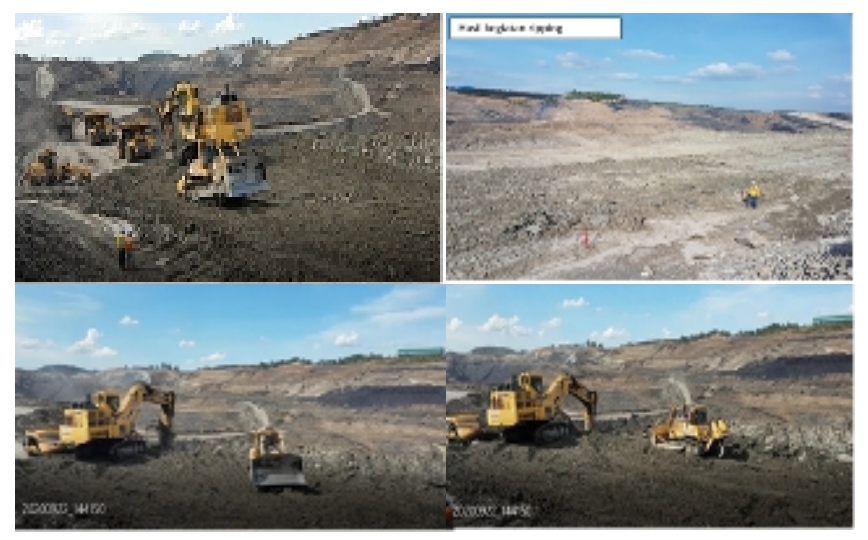

Gambar 7. Kegiatan ripping dan dozing

b. Produktivitas Ripping

Waktu siklus bulldozer dihitung dengan menggunakan Pers.(3) sebagai berikut:

\section{Diketahui}

Kapasitas blade (KB)

Jarak dorong (D)

Waktu maju dozer

Waktu mundur dozer

Waktu pergantiaan transmisi

$$
\begin{aligned}
& =22 \mathrm{~m}^{3} \\
& =20 \mathrm{~m} \\
& =34 \text { detik } \\
& =16 \text { detik } \\
& =3 \text { detik }
\end{aligned}
$$

$\mathrm{F}=20 / 34=0,59$

$\mathrm{R}=20 / 16=1,25$

$$
\begin{aligned}
\mathrm{CM} & =(20 / 0,59)+(20 / 1,25)+3 \\
& =34+16+3=53 \text { detik } \\
& =0,88 \text { menit }
\end{aligned}
$$

Produktivitas Bulldozer komatsu D375 dihitung dengan menggunakan Pers.(4) sebagai berikut:

\section{Diketahui:}

$\begin{array}{ll}\text { Kedalaman Penetrasi } & =1,2 \mathrm{~m} \\ \text { Panjang Area }(\mathrm{J}) & =20 \mathrm{~m} \\ \text { Efisiensi Kerja } & =0,75\end{array}$

$q_{r}=\frac{1 / 2 \times 1,2 \times 1,2 \times 60 \times 0,75}{0,88}=861 \mathrm{bcm} / \mathrm{jam}$

\section{c. Produktivitas Dozing}

Waktu edar Bulldozer D375 pada aktivitas RippingDozing dihitung dengan memakai Pers(3) seperti berikut:

\section{Diketahui:}

Kapasitas blade (KB)

$$
=22 \mathrm{~m}^{3}
$$

Jarak dorong(D)

Waktu maju dozer

Waktu mundur dozer

Waktu pergantiaan transmisi (Z)

$\mathrm{F}=20 / 56=0,36$

$\mathrm{R}=20 / 16=1,25$

$$
\begin{aligned}
\mathrm{CM} & =(20 / 0,36)+(20 / 1,25)+3 \\
& =56+16+3=75 \text { detik } \\
& =1,25 \text { menit }
\end{aligned}
$$

Produktivitas Bulldozer pada aktivitas Dozing dihitung dengan menggunakan Pers.(7) sebagai berikut:

Diketahui

Kapasitas blade (KB)

Jarak dorong (D)

Waktu maju dozer

Waktu mundur dozer

$=20 \mathrm{~m}$

$=56$ detik

$=16$ detik

$=3$ detik

$$
\text { Efisiensi Kerja } \quad=0,75
$$

$$
\begin{aligned}
q_{d} & =\frac{22 \times 60 \times 0,75}{1,25} \\
& =792 \mathrm{BCM} / \mathrm{jam}
\end{aligned}
$$

d. Kapasitas produksi Ripping-Dozing

Kapasitas produksi Ripping-Dozing dihitung menggunakan Pers.(8), sebagai berikut:

$$
\begin{aligned}
q_{r d} & =\frac{792 \times 861}{792+861} \\
& =413 \mathrm{~m}^{3} / \mathrm{jam}
\end{aligned}
$$

e. Produktivitas Alat Angkut

Alat angkut yang digunakan untuk mengangkut material clay stone dari loading excavator komatsu PC 2000 adalah dumptruck komatsu HD 785,dengan jarak tempuh dari loading point ke disposal 4,6 km.

Produktivitas dumptruck komatsu HD785 dihitung menggunakan Pers.(5) sebagai berikut:

Diketahui:

$\begin{array}{ll}\text { Kapasitas bucket }(\mathrm{KB}) & =12 \mathrm{~m}^{3} \\ \text { Banyak pengisian }(\mathrm{n}) & =5 \mathrm{kali} \\ \text { Faktor bucket }(\mathrm{Fb}) & =100 \% \\ \text { Effisiensi kerja (Eff) } & =76 \% \\ \text { Swell factor (SF) }=0,87 & \\ \text { Cycle time HD 785 } & =24,23 \text { menit } \\ & =1453,8 \text { detik }\end{array}$

$P=\frac{3600}{1453,8} \times 5 \times 12 \times 100 \% \times 0,76 \times 0,87=113,57 \mathrm{bcm} / \mathrm{jam}$

f. Keserasian Alat Gali-Muat dan Angkut

Keserasian alat gali-muat dan angkut diitung menggunakan Pers.(6), sebagai berikut: 


$$
\begin{aligned}
\mathrm{MF} & =(5 \times 6 \times 47) /(1 \times 1453,8) \\
& =1410 / 1453,8 \\
& =0,97
\end{aligned}
$$

Berdasarkan hasil perhitungan terlihat bahwa bernilai 0,97 artinya nilai $\mathrm{MF}<1$ dimana alat angkut bekerja penuh, alat muat mempunyai waktu tunggu.

Berdasarkan kajian di atas maka diperoleh perbandingan produktivitas alat gali-muat, alat angkut, dan alat Ripping dengan hanya melakukan aktivitas Ripping saja dibandingkan dengan melakukan aktivitas RippingDozing, sebagaimana disajikan pada Tabel 1 berikut.

Tabel 1. Perbandingan produktivitas alat gali-muat, alat angkut, dan alat ripping dengan hanya melakukan aktivitas ripping dibandingkan dengan melakukan aktivitas ripping-dozing

\begin{tabular}{|c|c|c|c|c|c|c|c|c|}
\hline \multirow{2}{*}{ No } & \multirow{2}{*}{ Unit } & \multirow{2}{*}{ Jumlah } & \multicolumn{2}{|c|}{ Cycle time (detik) } & \multicolumn{2}{|c|}{$\begin{array}{c}\text { Produktivitas } \\
\text { (BCM/jam) }\end{array}$} & \multicolumn{2}{|c|}{ MF } \\
\cline { 4 - 7 } & & & $\mathrm{A}$ & $\mathrm{B}$ & $\mathrm{A}$ & $\mathrm{B}$ & $\mathrm{A}$ & $\mathrm{B}$ \\
\hline 1 & PC 2000 & 1 & 59 & 45 & 415 & 640 & \multirow{2}{*}{1,19} & \multirow{2}{*}{0,97} \\
\hline 2 & $\begin{array}{l}\text { Bulldozer } \\
\text { D375 }\end{array}$ & 1 & 44 & 64 & 864 & 413 & & \\
\hline 3 & HD 785 & 6 & 1462,2 & 1453,8 & 101,62 & 113,57 & & \\
\hline
\end{tabular}

Keterangan: $\mathrm{A}=$ Aktivitas Ripping

$\mathrm{B}=$ Aktivitas Ripping-Dozing

Berdasarkan Tabel 1 terlihat bahwa pengupasan tanah penutup dengan aktivitas Ripping-Dozing jauh lebih efektif dilakukan dalam mencapai target produksi yang diinginkan perusahaan sebesar $640 \mathrm{BCM} / \mathrm{jam}$ untuk alat gali-muat.

\section{KESIMPULAN}

Hasil penelitian menunjukkan hasil bahwa produktivitas alat angkut (excavator komatsu PC 2000) meningkat dari $415 \mathrm{BCM} / /$ jam saat dilakukan Ripping menjadi 640 BCM/jam saat dilakukan aktivitas Ripping-Dozing. Hal ini menyebabkan produkivitas dari alat angkut juga meningkat dari 101,62 $\mathrm{BCM} / \mathrm{jam}$ menjadi 113,57 $\mathrm{BCM} / \mathrm{jam}$. Produktivitas bulldozer menurun dari 864 $\mathrm{BCM} / \mathrm{jam}$ menjadi $413 \mathrm{BCM} / \mathrm{jam}$. Artinya, aktivitas Ripping-Dozing lebih efektif digunakan dalam kegiatan pemberaian material overburden ditunjukkan dengan meningkatnya produktivitas dari alat gali-muat dan angkut, sehingga target produksi dapat dicapai.

\section{DAFTAR PUSTAKA}

[1] Juniah, R., Rahmi, H. (2017). The Influence of Sand Mining towards the Sustainability of Power Support and Capacity of Lambidaro River. AIP
Conference Proceedings 1903: 040015-1 040015-6.

[2] Juniah, R., (2018). Study of Carbon Value of the Allotment of Former Coal Mining Land of PT Samantaka Batubara for Sustainable Mining Environment. Journal of Sustainable Development, 11 (4): 213-227.

[3] Puspita, M., Rahman, A., Abuamat HAK, (2015). Kajian Teknis Dan Ekonomis Pemberaian Interburden B2C Secara Ripping Pada Tambang Banko Barat Pit-1 Timur, PT Bukit Asam (Persero), Tbk. UPTE, Sumatera Selatan. Jurnal Ilmu Teknik Sriwijaya. 3 (2).

[4] Sebastian, R., Toha, M. T., Bochori. (2018). Analisis Metode Ripping Untuk Mengoptimalkan Fragmentasi Batubara Dalam Rangka Meningkatkan Produktivitas Excavator Backhoe Di Tambang Banko Barat PT Bukit Asam (Persero), Tbk. Jurnal Pertambangan. 2 (3) : $1-10$.

[5] Sahu, Rajat Kumar. (2012). Application Of RipperDozer Combination In Surface Mines: Its Applicability And Performance Study. Rourkela: Department Of Mining Engineering National Institute Of Technolgy.

[6] Yeni, F. D., Yulhendra, D., (2019), Analisa Ekonomi Penggalian Overburden dengan Menggunakan Metode Penggaruan Dibandingkan dengan Metode Peledakan pada Penambangan Batubara PT Madhani Talatah Nusantara Site Gendang Timburu Kotabaru Kalimantan Selatan. Jurnal Bina Tambang. 4 (1).

[7] Sudrajat, F. R., Purwoko, B., Syafrianto, M. K., (2019). Perencanaan Kebutuhan Alat Galimuat Dan Alat Angkut Untuk Mencapai Target Produksi Overburden Pada Penambangan Batubara Di Pt. Ganda Alam Makmur Kecamatan Kaubun Kabupaten Kutai Timur Provinsi Kalimantan Timur. Jurnal Elektronik Laut, Sipil, Tambang. 6 (1): 169178.

[8] Sumarta, F., Anaperta, Y.M., (2020). Optimalisasi Produktivitas Overburden Menggunakan Metode Quality Control Circle (QCC) Untuk Evaluasi Ketidaktercapaian Target Produksi Bulan Desember Tahun 2019 Pada PT. Triaryani Kabupaten Musi Rawas Utara, Sumatera Selatan. Jurnal Bina Tambang. 5 (3):123-132.

[9] Purwanto, T., Wiranto, P., Lukman, H. (2016). Produktivitas Alat Berat Pada Pembangunan 
Jalan Ruas Laratlamdesar Provinsi Maluku. Jurnal Online Mahasiswa (JOM) Bidang Teknik Sipil, 1 (1): 1-13

[10] Nofwanda, A., R. (2019) Analisis Parameter Yang Mempengaruhi Produksi Alat Gali-muat Dan Alat Angkut Pada Penambangan Batubara Pit 2 Banko Barat PT Bukit Asam Tbk, Tanjung Enim, Sumatera Selatan. Skripsi tidak diterbitkan. Jurusan Teknik Pertambangan Universitas Sriwijaya.

[11] Siregar, A. A., dan Sumarya (2018). Studi Analisis dan Simulasi Peningkatan Produktivitas Exvator Hitachi EX 1900-6 Dalam Pengupasan Overburden Pada Tambang Batubara PT. Mandala Karya Prima Jobsite PT. Mandiri Inti Perkasa Provinsi Kalimanta Timur. Jurnal Bina Tambang. 3 (4).

[12] Choudhary, R. P. (2015). Optimization Of LoadHaul-Dump Mining System By OEE and Match Factor For Surface Mining. International Journal of Applied Engineering and Technology. 5 (2): 96-102. 